\title{
Tropical Journal of Pathology and Microbiology

\section{A study to correlate smear microscopy and rapid antigen detection techniques in the diagnosis of malaria}

\author{
Shameem K. ${ }^{1}$, Chandra T. ${ }^{2 *}$
}

DOI: https://doi.org/10.17511/jopm.2020.i01.14

\author{
${ }^{1}$ Khatija Shameem, Associate Professor, Department of Pathology, KIMS, Narketpally, Telangana, India. \\ 2* T. Jaya Chandra, Associate Professor, Department of Microbiology, GSL Medical College, Rajahmundry, Andhra Pradesh, India.
}

Introduction: Malaria is an endemic, tropical protozoan infection caused different Plasmodium species. Materials and Methods: Study was conducted in the Department of Microbiology, GSL Medical College for 6 months. Peripheral blood smear stained by Giemsa technique ad commercially available rapid antigen detection kits were used for the diagnosis of malaria. Results: Among 98 the clinically diagnosed malaria cases in this study, $69(70.4 \%)$ cases were identified as malaria positive. Out of these, $68 \%$ (47) were positive by blood smear examination and $87 \%$ (60) were positive by kit method and in the positive cases 35 were male and 34 were female participants. Conclusion: Rapid diagnostic tests were more sensitive in the diagnosis of malaria. However, other confirmatory tests such as PCR should be considered because some clinically proved cases were missed.

Keywords: Among, Blood smear, Malaria, Plasmodium

Corresponding Author

T. Jaya Chandra, Associate Professor, Department of Microbiology, GSL Medical College, Rajahmundry, Andhra Pradesh, India.

Email: chanduthegreat2014@gmail.com
How to Cite this Article

Shameem K, Chandra TJ. A study to correlate smear microscopy and rapid antigen detection techniques in the diagnosis of malaria. Trop J Pathol Microbiol. 2020;6(3):89-93. Available From: https://pathology. medresearch.in/index.php/jopm/article/view/421
To Browse

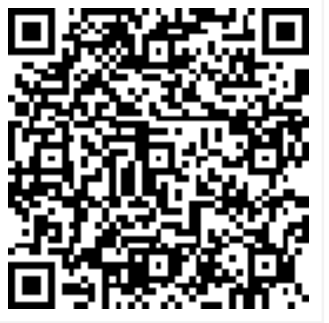

\section{Introduction}

Malaria is an endemic, tropical protozoan infection caused different Plasmodium species. Plasmodium falciparum, Plasmodium vivax, Plasmodium malariae, Plasmodium ovale and Plasmodium knowlesi are the members of plasmodium that cause malaria [1,2]. Malaria is a serious infection, leads to death if not treated properly. As per the available reports, worldwide, the prevalence of malaria was reported as 300 million per annum [3, 4]. In malaria, symptoms such as fever, rigors, anemia, enlargement of spleen, liver and

Manuscript Received 10-01-2020

Review Round 1
20-01-2020
Funding
Nil

Conflict of Interest No
So on were reported. Among the members, of plasmodium members, malaria caused by $P$. falciparum is severe, leads to death especially in children due to involvement of brain, cerebral malaria. But malaria caused by $P$. vivax was considered to be mild but leads to death. As per the recent studies, the global death rate due to vivax malaria was reported to be $0.10-1.6 \%$ [5]. Due to large number of cases and deaths, government of India inaugurated anti malaria programme in 1953, Different diagnostic methods such as peripheral blood smear, serodiagnistics, antigen demonstration, molecular methods being practiced for the diagnosis of this killer

\begin{tabular}{|c|c|c|}
\hline $\begin{array}{c}\text { Review Round } 2 \\
26-01-2020\end{array}$ & Review Round 3 & $\begin{array}{c}\text { Accepted } \\
30-01-2020\end{array}$ \\
\hline $\begin{array}{c}\text { Ethical Approval } \\
\text { Yes }\end{array}$ & $\begin{array}{c}\text { Plagiarism X-checker } \\
17 \%\end{array}$ & Note \\
\hline
\end{tabular}


Parasitic infection. Several advantages and disadvantages were reported for these techniques. With these, a study was conducted to find the correlation between the peripheral blood smear and antigen demonstration for the detection of malaria.

\section{Materials and Methods}

Settings: Study was conducted in the department of Microbiology, GSL Medical College.

Duration of study: Study was conducted for 6 months, September 2018 to February 2019.

Sampling method: Random sampling was considered in this study.

Inclusion criteria: Individuals clinically diagnosed as malaria, aged $>18$ years, who submitted informed consent, were included in the study.

Exclusion criteria: Individuals aged $<18$ years, who didn't submitted informed consent, were excluded in the study.

Sample size: All the individuals who satisfy the inclusion criteria during the study period were included in the study.

Finger prick technique was used to collect blood for peripheral smear. Two new, grease free glass slides were used for thick and thin smear preparation, Giemsa stain was used to the smears as per the WHO guidelines $[7,8]$. The stained smears were examined under 100X objectives using light microscope. A minimum of 100 to 200 fields were screened for the diagnosis of malaria. Smears were screened for the detection of various morphological stages inside the RBC such as ring forms, gametocytes.

Commercially available, rapid malaria Pan+Pf cards were used for antigen. First, the test kits were brought to the room temperature before the procedure and. As per the manufacture guidelines, by using sample dropper provided with the test kit, whole blood was pipetted up to the mark and dispensed on the sample well $\mathrm{S}$. this step was followed by adding three drops of buffer to the well B. Then the results were read after 20 minutes time. Presence of three purple to pink lines in the regions of $F, P$ and $C$ indicated that the sample was reactive for $P$. falciparum, $P$. vivax and other species like $P$. malariae and $P$. ovale. Whereas, band at $C$ and $F$ region indicated that the sample was positive only for $P$. falciparum. If the bands were seen on $C$ and $P$, the sample was considered positive to all other Plasmodium species. Presence of one band on $C$ region even after 20 minutes indicates the test is negative.

\section{Results}

Among 98 the clinically diagnosed malaria cases in this study, $69(70.4 \%)$ cases were identified as malaria positive. Out of these, 68\% (47) were positive by blood smear examination and $87 \%$ (60) were positive by kit method (Table 1 ).

Table-1: Comparison of the techniques.

\begin{tabular}{|l|l|c|l|}
\hline \multicolumn{1}{|c|}{ Technique } & Positive & $\%$ & \multicolumn{1}{|c|}{ Cost per test in rupees } \\
\hline Blood smear & 47 & 68 & $10-15$ \\
\hline Kit method & 60 & 87 & 100 \\
\hline
\end{tabular}

In this study total 69 samples were diagnosed to be malaria. In this 35 were male and 34 were female participants, with male female ratio 35:34. When ages of the participants was considered, 10 were positive in 18-28 age group, 16 were positive in 2939 years age group, 11 were positive in $40-50$ years age group, 15 were positive in 51-60 age group and 17 were positive in $>61$ years age group. Whereas when gender was considered, among male, 7 were positive in 18-28 age group, 9 were positive in 29-39 years age group, 5 were positive in 40-50 years age group, 8 were positive in 51-60 age group and 6 were positive in $>61$ years age group. Whereas among female, 3 were positive in 18-28 age group, 7 were positive in 29-39 years age group, 6 were positive in $40-50$ years age group, 7 were positive in 51-60 age group and 11 were positive in $>61$ years age group (Table 2 ).

Table-2: Age wise test results culture result among nondiabetic individuals; $\mathbf{n}(\%)$.

\begin{tabular}{|l|l|l|l|}
\hline \multicolumn{1}{|c|}{ Age } & \multicolumn{1}{c|}{ Male } & \multicolumn{1}{c|}{ Female } & \multicolumn{1}{c|}{ Total } \\
\hline $18-28$ & 7 & 3 & 10 \\
\hline $29-39$ & 9 & 7 & 16 \\
\hline $40-50$ & 5 & 6 & 11 \\
\hline $51-60$ & 8 & 7 & 15 \\
\hline$>61$ & 6 & 11 & 17 \\
\hline Total & $35(51)$ & $34(49)$ & $69(100)$ \\
\hline
\end{tabular}

\section{Discussion}

Malaria diagnosis has to be considered to be health emergency and there should not be any delay in the diagnosis. But the malaria diagnosis is a significant challenge in the medical field $[2,9]$. Smear microscopy is commonly practiced technique not only for the diagnosis but also treatment monitoring, to note the drug resistance of malaria. In most of the settings, perheral blood smear reared from fingertip blood is being used for the diagnosis of malaria. But requirement of prolonged time 
Period, technical expertise are the major draw backs. Inspite of these draw backs, low cost is the major factor for considering smear microscopy for the diagnosis of malaria in the study. Several reports mentioned that requirement of trained microscopist and prolonged time period are the major draw backs of this technique. But in tertiary health care setup, manpower is not an issue because every institution has to recruit the manpower as per the norms. Moreover, various paramedical as well as nursing students are the additional asset where the majority work is being carried by them as a part of their training. Hence manpower is not an issue in tertiary health care units especially in India. In this study, 68\% (47) cases were diagnosed as malaria by using peripheral blood smear (Table 1). Whereas it was reported to be $75 \%$ and $62 \%[11,12]$. Coleman RE et al., quoted that microscopy is the gold standard technique for the diagnosis of malaria [13]; Inspite of this the authors reported $10 \%$ false positive results $[14,15,16]$. In another report by Abisha Jaya Singh et al., the sensitivity was reported to be $75 \%$; but the specificity as well as positive predictive values were reported to be $100 \%$ for microscopy [17]. Whereas Gulrez et al., [11] reported that the peripheral blood smear positivity was $61 \%$. The hope behind the development of rapid malaria diagnostic technique was rapidity, low price and accuracy [18]. The rapid diagnostics were also proved to be the backbone for the diagnosis of malaria especially in the areas where the microscopic facilities are not available $[8,19]$. In this report, the antigen detection by kit methods detected $87 \%$ (60) cases. Santhy et al., reported that the malaria positivity with the kit methods was $52.4 \%$; but the specificity was reported to be $85 \%$ and PPV was $62.5 \%$ [10]. The investigators reported that smear and antigen detection have similar specificity and PPV [17]. The range of sensitivity with kit method was ranged $76-98 \%$ [20]. The findings of the present study were similar to the available reports [21]. There were 19 cases missed by the peripheral smear microscopy. Among the missed cases, the cause was identified to be $P$. falciparum by the rapid diagnostic tests. As per the reports, this could be due to sequestration which is the important virulence in case of $P$. falciparum [22]; this is nothing but holding back of the parasite in the capillaries of the internal organs. When gender was considered, $51 \%$ (35) and 49\% (34) cases were diagnosed as malaria positive respectively for male and female category. Abisha
Jaya Singh et al., reported that the $80 \%$ and $20 \%$ cases were diagnosed to be malaria respectively in the gender [17]. It was reported in the literature that more outdoor activity is the major cause for more positive results in the male group. But all the present study participants had outdoor activity because most $(85 \%)$ of these were daily labor and the remaining were employees. So surely the exposed to the bite of anopheles mosquito. Due to this outdoor activity, the malaria positivity was similar in the gender. Age wise, malaria positivity was increased with the age in this study; this is also due to more outdoor activity.

Limitations of the study: Small sample size, short duration of the study are the limitations of the study.

\section{Conclusion}

Rapid diagnostic tests were more sensitive in the diagnosis of malaria. However, other confirmatory tests such as PCR should be considered because some clinically proved cases were missed.

\section{What the study adds to the existing knowledge?}

The present study aimed to establish the sensitivity in the diagnosis of malaria in GSL Medical College for 6 months, however the study also supports the fact that far more inclusive test are required such as PCR to determine the diagnosis in a broader manner.

\section{Authors contributions}

Dr. Khatija Shameem: Literature survey, data analysis, paper writing, Dr. T Jaya Chandra: Sample collection, Bench work, statistical analysis, paper writing

\section{Reference}

01. Santhy B, Ravichandran T, Ramani CP, Sumathy $P$, Heber A. Rapid Laboratory Techniques in Diagnosis of Malaria in a Tertiary Care Hospital, Chennai. Int J Sci Stud. 2016;3(11)94-99. doi: $\quad 10.17354 /$ ijss/2016/64[Crossref]

02. Kumar A, Valecha N, Jain T, Dash AP. Burden of malaria in India- Retrospective and prospective view. The Am J Trop Med Hyg. 2007;77(6)6978.

[Crossref] 
03. Mukry SN, Madiha S, Gul S, Kashif S, Shamsi AN, Tahir S. Laboratory Diagnosis of MalariaComparison of Manual and Automated Diagnostic Tests. Canadian J Infec Diseases and Med Microb. 2017;1-7.

doi: $\quad 10.1155 / 2017 / 9286392[$ Crossref]

04. World Health Organization. Basic Malaria Microscopy- Part I Learner's Guide; Part II Tutor's Guide. Geneva- World Health Organization. 1991.

Available at[Article][Crossref]

05. Ahmed R, Devnath K, Bhowmik D, Sharma I. High-sensitivity detection of human malaria parasites by the use of rapid diagnostic tests and nested polymerase chain reaction in burdened communities of North East India. Indian J Med Microbiol. 2018;36(4)541-546.

doi:10.4103/ijmm.IJMM_18_394[Crossref]

06. Srinivasan S, Moody AH, Chiodini PL. Comparison of blood-film microscopy, the

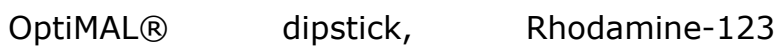
fluorescence staining and PCR, for monitoring antimalarial treatment. Ann Trop Med Parasitol. 2000;94(3)227-232.

doi: $10.1080 / 00034980050006393$ [Crossref]

07. Price RN, Douglas NM, Anstey NM. New developments in Plasmodium vivax malariasevere disease and the rise of chloroquine resistance. Curr Op Infectious Dis. $2009 ; 22(5) 430-435$.

doi: 10.1097/QCO.0b013e32832f14c1[Crossref]

08. Coleman RE, Sattabongkot J, Promstaporm S, Maneechai N, Tippayachai B, Kengluecha A, et al. Comparison of PCR and microscopy for the detection of asymptomatic malaria in a Plasmodium falciparum/vivax endemic area in Thailand. Malaria J. 2006;5(1)121.

doi: 10.1186/1475-2875-5-121[Crossref]

09. Kamel MM, Attia SS, Emam GD, Al Sherbiny NA. The validity of rapid malaria test and microscopy in detecting malaria in a preelimination region of Egypt. Scientifica. 2016;2016.

doi: $10.1155 / 2016 / 4048032$ [Crossref]
10. Bharti AR, Patra KP, Chuquiyauri $R$, Kosek $M$, Gilman RH, Llanos-Cuentas $A$, et al. Polymerase chain reaction detection of Plasmodium vivax and Plasmodium falciparum DNA from stored serum samples- implications for retrospective diagnosis of malaria. Am J Trop Med Hyg. 2007;77(3)444-446.

[Crossref]

11. Snow RW, Guerra CA, Noor AM, Mvint HYSI. The global distribution of clinical episodes of $P$ falciparum malaria. Nature. 2005;434(7030)214-217. doi: $10.1038 /$ nature03342[Crossref]

12. Murray CK, Bell D, Gasser RA, Wongsrichanalai C. Rapid diagnostic testing for malaria. Trop Med Int Health. $2003 ; 8(10) 876-883$. doi: $10.1046 / j .1365-3156.2003 .01115 . x[$ Crossref]

13. Wongsrichanalai C, Barcus MJ, Muth S, Sutamihardja A, Wernsdorfer WH. A review of malaria diagnostic tools- Microscopy and rapid diagnostic test (RDT). Am J Trop Med Hyg. 2007;77(6)119-127.

[Crossref]

14. Sturrock HJ, Hsiang MS, Cohen JM, Smith DL, Greenhouse B, Bousema T, et al. Targeting asymptomatic malaria infections- Active surveillance in control and elimination. PLoS Medicine. 2013;10(6)e1001467.

doi:10.1371/journal.pmed.1001467[Crossref]

15. WHO SE Asia. Implementation of collaborative activities on Roll back Malaria in SE Asia region. WHO. New Delhi, 2000;1-21.

Available at[Article][crossref]

16. Nandwani S, Mathur M, Rawat S. Evaluation of the direct acridine orange staining method and QBC test for diagnosis of malaria in Delhi, India. J Comm Dis. 2003;35(4)279-282.

[Crossref]

17. Jayasingh A, Rompicherla V, Radha RK, Shanmugam P. Comparative Study of Peripheral Blood Smear, Rapid Antigen Detection, ELISA and PCR Methods for Diagnosis of Malaria in a Tertiary Care Centre. J Clinic Diagnos Res. 2019 ;13(1)DC08-DC11.

doi: $10.7860 / J C D R / 2019 / 38213.12483$ [Crossref] 
18. Santhy B, Ravichandran T, Ramani CP, Sumathy $P$, Heber A. Rapid Laboratory Techniques in Diagnosis of Malaria in a Tertiary Care Hospital, Chennai. Int J Sci Stud. 2016;3(11)94-99.

doi: $\quad 10.17354 /$ ijss/2016/64[Crossref]

19. Parija SC, Dhodapkar R, Elangovan S, Chaya DR. A comparative study of blood smear, QBC and antigen detection for diagnosis of malaria. Indian J Pathol Microbiol. 2009;52(2)200-202. [Crossref]

20. Parija SC, Dhodapkar R, Elangovan S, Chaya DR. A comparative study of blood smear, QBC and antigen detection for diagnosis of malaria. Indian J Pathol Microbiol. 2009;52(2)200-202.

[Crossref]
13. Gulrez M, Varshney KR, Singh YI. Comparative Study of Various Techniques in Diagnosis of Malaria. Sch J App Med Sci. 2014;2(6C)30603063.

[Crossref]

14. Singh N, Bharti PK, Singh MP, Mishra S, Shukla MM, Sharma RK, Singh RK. Comparative evaluation of bivalent malaria rapid diagnostic tests versus traditional methods infield with special reference toheat stability testing in central India. PLoS ONE. 2013;8(3)e58080. doi: 10.1371 /journal.pone. 0058080 [Crossref] 